\title{
The Cost of Capital in International Financial Markets: Local or Global
}

Citation for published version (APA):

Kool, C. J. M., Koedijk, C. G., Schotman, P. C., \& van Dijk, M. A. (2002). The Cost of Capital in International Financial Markets: Local or Global. Journal of International Money and Finance, 21(6), 905929. https://doi.org/10.1016/S0261-5606(02)00028-1

Document status and date:

Published: 01/01/2002

DOI:

10.1016/S0261-5606(02)00028-1

Document Version:

Publisher's PDF, also known as Version of record

\section{Please check the document version of this publication:}

- A submitted manuscript is the version of the article upon submission and before peer-review. There can be important differences between the submitted version and the official published version of record.

People interested in the research are advised to contact the author for the final version of the publication, or visit the DOI to the publisher's website.

- The final author version and the galley proof are versions of the publication after peer review.

- The final published version features the final layout of the paper including the volume, issue and page numbers.

Link to publication

\footnotetext{
General rights rights.

- You may freely distribute the URL identifying the publication in the public portal. please follow below link for the End User Agreement:

www.umlib.nl/taverne-license

Take down policy

If you believe that this document breaches copyright please contact us at:

repository@maastrichtuniversity.nl

providing details and we will investigate your claim.
}

Copyright and moral rights for the publications made accessible in the public portal are retained by the authors and/or other copyright owners and it is a condition of accessing publications that users recognise and abide by the legal requirements associated with these

- Users may download and print one copy of any publication from the public portal for the purpose of private study or research.

- You may not further distribute the material or use it for any profit-making activity or commercial gain

If the publication is distributed under the terms of Article $25 \mathrm{fa}$ of the Dutch Copyright Act, indicated by the "Taverne" license above, 


\title{
The cost of capital in international financial markets: local or global?
}

\author{
Kees G. Koedijk ${ }^{\mathrm{a}, *}$, Clemens J.M. Kool ${ }^{\mathrm{b}}$, Peter C. Schotman ${ }^{\mathrm{b}}$, \\ Mathijs A. van Dijk ${ }^{a}$ \\ a Department of Financial Management, Erasmus University Rotterdam, P.O. Box 1738, 3000 DR \\ Rotterdam, The Netherlands \\ b Maastricht University, Maastricht, The Netherlands
}

\begin{abstract}
This paper analyzes to what extent international and domestic asset pricing models lead to a different estimate of the cost of capital for an individual firm under the maintained assumption of perfect international financial integration. We distinguish between (i) the multifactor Solnik-Sercu ICAPM including both the global market portfolio and exchange rate risk premia, and (ii) the single factor domestic CAPM. We use a sample of 3,293 stocks from nine countries in the period 1980-1999. The domestic CAPM yields a significantly different estimate of the cost of capital from the multifactor ICAPM for only five percent of the firms in our sample. We attribute the close correspondence between local and global pricing to strong country factors in individual stock returns, which are probably due to lack of real integration. Our results reinforce the home bias puzzle.
\end{abstract}

(C) 2002 Elsevier Science Ltd. All rights reserved.

\section{Introduction}

Theory suggests the use of an international CAPM (ICAPM) for computing a firm's cost of capital in a financially integrated world. In practice, however, a wide variety of asset pricing models that ignore the international dimension is used to compute the cost of capital. ${ }^{1}$ This may, among other things, be related to the fact

* Corresponding author. Tel.: +31-10-408-2748; fax: +31-10-408-9017.

E-mail address: c.koedijk@fbk.eur.nl (K.G. Koedijk).

1 A survey by Keck et al. (1998) indicates that practitioners often perform cost of capital computations in a way that is inconsistent with the theoretical foundations of international valuation. 
that even though the ICAPM is theoretically preferable to the domestic CAPM, a firm's beta calculated using the domestic CAPM does not necessarily provide an incorrect estimate of the cost of capital. The two asset pricing models could lead to the same cost of capital if the local stock market portfolio contains all the information that is relevant in order to price domestic assets internationally. ${ }^{2}$

The purpose of this paper is to empirically examine whether international and domestic asset pricing models really lead to a different estimate of the cost of capital. A partial answer is given by Stulz (1995b), who derives an expression for the difference in the estimation of a firm's beta when computed with the domestic CAPM as compared to the single factor ICAPM of Grauer et al. (1976). Stulz refers to this difference as the pricing error, which is linearly related to the computed cost of capital differential. Stulz uses data on the Swiss multinational Nestlé and finds a substantial pricing error.

We generalize the analysis of Stulz (1995b) in three ways. First, we employ the multifactor ICAPM of Solnik (1983) and Sercu (1980) including both the global market portfolio and exchange rate risk premia. ${ }^{3}$ Second, we derive statistical tests for the significance of the pricing error. Third, we use data on 3,293 stocks from nine different countries to investigate the difference between each of these models empirically. ${ }^{4}$ We analyze the sample period 1980:02-1999:06.

We find that the pricing error in terms of the cost of capital computed with either the domestic CAPM or the multifactor ICAPM of Solnik-Sercu is marginal. Only for about 5 percent of all firms in our sample the domestic CAPM yields a significantly different cost of capital than the multifactor ICAPM at the 95\% confidence level. We show that the absolute difference in the cost of capital amounts to about 50 basis points for the US, about 75 basis points for Germany and Japan, and similar amounts for the other countries in our sample. We argue that our findings may be attributed to strong country factors in the individual stock returns, consistent with the evidence of Heston and Rouwenhorst (1994) and Griffin and Karolyi (1998). A tentative explanation of this finding is a lack of real capital market integration, due to both cyclical and structural, and institutional country-specific factors. These closely tie together the fortunes of all firms operating in the same country. The observed differences between countries can and should be used by individual investors for the purpose of portfolio diversification. Diversification across industries within one country is insufficient to cope with a country's systemic risk according to our results. Our evidence reinforces the home bias puzzle.

Testing for a pricing error turns out to be very similar to testing for foreign

\footnotetext{
${ }^{2}$ See Stulz (1998) for an overview of the literature on globalization, asset pricing, and the cost of capital. We refer to Karolyi and Stulz (2002) for an alternative exposition of the conditions under which local and global asset pricing lead to the same result.

${ }^{3}$ In the benchmark ICAPM that Stulz (1995b) uses, exchange rate factors are omitted, since PPP is assumed to hold However, evidence abounds that substantial PPP deviations exist at a monthly horizon, see e.g. Abuaf and Jorion (1990) and Frankel and Rose (1996).

${ }^{4}$ Such wide coverage of firms and countries stands in contrast to most of the empirical literature, see for example Harvey (1991), Ferson and Harvey (1993), and Dumas and Solnik (1995).
} 
exchange exposure. We show how both methodologies are related and how pricing error tests can shed light on the well-known puzzle that firms from a variety of data sets show little exposure to exchange rate fluctuations. ${ }^{5}$

The paper is set up as follows. In Section 2, we review the international CAPM and the domestic CAPM and derive testable hypotheses. In Section 3, the data are described and summary statistics are discussed. Empirical results are presented in Section 4. Section 5 explores the results using a variance decomposition technique. We elaborate on the link between the pricing error tests and the foreign exchange exposure literature in Section 6. Summary and conclusions are presented in Section 7.

\section{The international CAPM and the domestic CAPM}

In this section, we develop tests to evaluate whether the domestic CAPM leads to a different cost of capital than the multifactor ICAPM. The starting point is the Solnik-Sercu version of the multifactor ICAPM. Assume a world with $N+1$ countries (currencies). The ICAPM has $N+1$ systematic risk factors: the global market portfolio and $N$ exchange rates. ${ }^{6}$ The model can be expressed as

$$
\mathrm{E}\left[R_{i}-r_{0}\right]=\mathrm{E}\left[R_{G}-r_{0}\right] d_{i 1}+\mathrm{E}\left[S+r-\iota r_{0}\right]^{\prime} d_{i 2},
$$

where $R_{i}$ and $R_{G}$ are the return of asset $i$ and the global market, respectively, expressed in the numeraire currency. The numeraire currency is the home currency 0 of asset $i$. $S$ represents the vector of nominal exchange rate returns of the other $l=1, \ldots, N$ countries against currency 0 . The vector $r$ denotes the nominal returns on the risk-free asset in country $l(l=1, \ldots, N) . r_{0}$ is the risk-free rate in the numeraire (home) country, and $\iota$ is a vector of ones. The global market beta and the exchange rate betas are defined as the regression coefficients $d_{i 1}$ and $d_{i 2}$ in

$$
R_{i}=\alpha_{1 i}+R_{G} d_{i 1}+S^{\prime} d_{i 2}+u_{i}=\alpha_{1 i}+Z^{\prime} d_{i}+u_{i},
$$

where $Z^{\prime}=\left(R_{G} S^{\prime}\right)$ and $\alpha_{1 i}=r_{0}\left(1-d_{i 1}\right)+\left(r-\iota r_{0}\right)^{\prime} d_{i 2}$ is a constant. The specific risk $u_{i}$, is orthogonal to $Z$. This version of the ICAPM is the maintained hypothesis for the rest of this paper.

In order to estimate $d_{i}$ we assume that the regression parameters are constant within a particular sample period. The risk premia on the global market and the currency factors may be time-varying though. ${ }^{7}$ Our empirical tests will be formulated in terms of hypotheses on the factor loadings $d_{i}$ for individual stocks relative to the global factors.

\footnotetext{
5 See Jorion (1990); Amihud (1994); Bodnar and Gentry (1993); Bartov and Bodnar (1994), and He and $\mathrm{Ng}$ (1998).

${ }^{6}$ Differences between the international asset pricing models of Solnik (1974, 1983); Grauer et al. (1976); Sercu (1980); Stulz (1981), and Adler and Dumas (1983) mainly arise from different assumptions with respect to the role of exchange rate factors and inflation differentials. See Stulz (1995a) for an overview of the literature. For a derivation of eq. (1) we refer to Sercu and Uppal (1995).

7 See for example Dumas and Solnik (1995).
} 
We follow Stulz (1995b) and consider the domestic CAPM as an alternative model,

$$
\mathrm{E}\left[R_{i}\right]=r_{0}+\mathrm{E}\left[R_{L}-r_{0}\right] b_{i}
$$

where $R_{L}$ is the return of the local market index expressed in the numeraire currency 0 . The beta of the domestic CAPM is defined as the regression slope in

$$
R_{i}=\alpha_{2 i}+R_{L} b_{i}+e_{i}
$$

The domestic CAPM posits a different decomposition into systematic and specific risk than the ICAPM. In order to compare the two models, we need to relate $R_{L}$ to the global factors $Z$.

Since eq. (2) applies to every individual stock, it also applies to the local market portfolio of every country. Applying (2) to $R_{L}$ we get

$$
R_{L}=\alpha_{L}+Z^{\prime} d_{L}+u_{L}
$$

where $u_{L}$ is orthogonal to $Z$. Substituting eq. (5) into (4) yields

$$
R_{i}=\alpha_{3 i}+Z^{\prime} d_{L} b_{i}+u_{L} b_{i}+e_{i}
$$

where $\alpha_{3 i}=\alpha_{2 i}+b_{i} \alpha_{L}$. Equations (2) and (6) lead to the same decomposition of systematic and specific risk if the local specific risk $e_{i}$ in eq. (4) is orthogonal to $Z$. In that case, the composite specific risk term $u_{L} b_{i}+e_{i}$ is orthogonal to $Z$ and eqs (2) and (6) are identical. But then the parameters in eqs (2) and (6) must be the same too, implying

$$
d_{i}=d_{L} b_{i}
$$

If the restrictions (7) hold, no pricing error results from using the domestic CAPM instead of the ICAPM. We call a test for this null-hypothesis a "Pricing Error" test. It tests the orthogonality between the global factors and the residuals from the domestic CAPM regression (4). A simple way to implement the test is to add the global instruments $Z$ to the domestic CAPM regression,

$$
R_{i}=\alpha_{4 i}+R_{L} \beta_{i}+Z^{\prime} \delta_{i}+v_{i},
$$

and test the null hypothesis $\mathrm{H}_{0}: \delta_{i}=0$. If the restriction holds, the risk that is diversifiable domestically is also diversifiable globally. Consequently, the domestic market portfolio contains all the information that is relevant to price assets. On the other hand, if risk that is diversifiable domestically contains risk that is systematic in the world market, the domestic CAPM incorrectly ignores such risk. The ICAPM will require a risk premium, however. In that case, the domestic CAPM leads to a different cost of capital than the ICAPM.

Rejection of (7) can be due to either the condition on the beta of the global market portfolio $\left(d_{i 1}=d_{L 1} b_{i}\right)$, the exchange rate betas $\left(d_{i 2}=d_{L 2} b_{i}\right)$, or both. If rejection occurs because of violation of the exchange rate restrictions $d_{i 2}=d_{L 2} b_{i}$, the impact on the estimated cost of capital might nevertheless be zero if required foreign exchange 
risk premia $\mathrm{E}\left[S+r-\iota r_{0}\right]$ are zero. ${ }^{8}$ Therefore, whether only the first restriction in eq. (7) is violated within the framework of the multifactor ICAPM is of interest under the assumption that exchange rate risk premia are zero. In Appendix A we show that eq. (8) can be reparameterized such that the pricing errors $p_{i}=d_{i}-d_{L} b_{i}$ are obtained directly as parameters, leading to the regression model

$$
R_{i}=\alpha_{4 i}+R_{L} b_{i}+Z^{\prime}{ }_{\perp} p_{i}+v_{i}
$$

where $Z_{\perp}=Z-u_{L} \gamma_{L}^{\prime}$, and $\gamma_{L}$ is a vector of parameters such that $Z_{\perp}$ is orthogonal to $R_{L}$ by construction. We test the null-hypothesis that the first element of $p_{i}$ is equal to zero. We call this the "Global Beta" test. If the null-hypothesis is rejected, the direct ICAPM beta $d_{i 1}$ will differ significantly from the indirect beta $d_{L 1} b_{i}$.

Even if exchange rate risk is not priced, the "Pricing Error" test still uses regression (8) with exchange rates included. Karolyi and Stulz (2002) derive a similar orthogonality condition for the single factor ICAPM in a world with instantaneous Purchasing Power Parity. In their model, $Z$ only contains the return on the global market portfolio $R_{G}$. Our model simplifies to their specification if all currency betas $d_{i 2}$ are zero. We refer to a test of this hypothesis as the "Currency Betas" test. It tests the null hypothesis that $d_{i 2}=0$ in regression (2). For a final test we consider the hypothesis $\mathrm{H}_{0}: d_{i 1}=0$, conditional on first setting $d_{i 2}=0$. This is a test of a pricing error between the domestic CAPM and the single factor ICAPM. Table 1 presents a brief summary of the hypotheses underlying the different tests.

Our analysis concerns the potential differences between expected returns implied

Table 1

Summary of null-hypotheses, purposes and underlying model structures of the test statistics

\begin{tabular}{llll}
\hline Test & Regression model & $\mathrm{H}_{0}$ & Issue \\
\hline Pricing error & $R_{i}=\alpha_{4 i}+R_{L} b_{i}+Z^{\prime}{ }_{\perp} p_{i}+v_{i}$ & $p_{i}=0$ & $\begin{array}{l}\text { Pricing error of domestic CAPM } \\
\text { versus multifactor ICAPM }\end{array}$ \\
Global beta & $R_{i}=\alpha_{4 i}+R_{L} b_{i}+Z^{\prime}{ }_{\perp} p_{i}+v_{i}$ & $\begin{array}{l}\text { first } \\
\text { element } \\
\text { of } p_{i}=0\end{array}$ & $\begin{array}{l}\text { Beta error of domestic CAPM } \\
\text { versus multifactor ICAPM }\end{array}$ \\
$\begin{array}{lll}\text { Pricing error } \\
\text { single factor }\end{array}$ & $R_{i}=\alpha_{6 i}+R_{L} \varphi_{i}+R_{G} \theta_{i}+w_{i}$ & $\theta_{I}=0$ & $\begin{array}{l}\text { Pricing error of domestic CAPM } \\
\text { versus single factor ICAPM }\end{array}$ \\
Exposure & $R_{i}=\gamma_{0 i}+R_{L} \gamma_{1 i}+S^{\prime} \gamma_{2 i}+\varepsilon_{i}$ & $\gamma_{2 i}=0$ & $\begin{array}{l}\text { e.r. exposure controlled for local } \\
\text { market return }\end{array}$ \\
Total exposure & $R_{G}=c_{1}+S^{\prime} f_{G S}+\eta_{G}$ & $c_{1 i}=0$ & $\begin{array}{l}\text { e.r. exposure controlled for } \\
\text { orthogonalized local and global } \\
\text { market return }\end{array}$ \\
& $\begin{array}{l}R_{L}=c_{2}+R_{G} f_{L G}+S^{\prime} f_{L S}+\eta_{L} \\
R_{i}=c_{0 i}+S^{\prime} c_{1 i}+\eta_{G} c_{2 i}+\eta_{L} c_{3 i}+v_{i}\end{array}$ & $d_{i 2}=0$ & $\begin{array}{l}\text { e.r. exposure controlled for global } \\
\text { market return }\end{array}$ \\
Currency Betas & $R_{i}=\alpha_{1 i}+R_{G} d_{i 1}+S^{\prime} d_{i 2}+u_{i}$ & &
\end{tabular}

\footnotetext{
${ }^{8}$ For an overview of the literature on exchange rate risk we refer to Dumas and Solnik (1995) and Engel (1996).
} 
by ICAPM and those implied by the standard domestic betas. We will not test hypotheses on the cross-section of $\alpha_{i}$ 's. For the domestic CAPM it has been well documented that betas cannot explain the cross-section of expected returns, and that $\alpha_{i}$ differs systematically from zero for portfolios sorted on market capitalization size or book-to-market ratio. Fama and French (1998) show that these empirical results hold both for the US and many other countries. Our tests can be interpreted as an examination of the issue whether international risk factors imply different expected returns than the local market factor and could consequently be used in explaining the asset pricing anomalies of the domestic CAPM.

\section{Data}

In the empirical analysis we use monthly data for nine industrialized countries: Australia, Canada, France, Germany, Japan, the Netherlands, Switzerland, United Kingdom, and the United States. Nominal exchange rates for all countries are taken from the International Financial Statistics (IFS) tape (line ae). In the empirical application we consider the period 1980:02-1999:06.

The market weighted local equity indices and the market weighted global market index are from Morgan Stanley Capital International (MSCI). Table 2 shows that the nine countries jointly account for approximately 91 percent of the MSCI marketweighted world index in July 1994. Australia, Canada, France, Germany, the Netherlands, and Switzerland are each less than 4 percent of the MSCI market-weighted world index. The United States take approximately 36 percent of the index.

Data on individual stocks in this study are obtained from Datastream. We have

Table 2

Composition of MSCI index and sample

This table presents an overview of the composition of the MSCI World index on July 29,1994 (source: Morgan Stanley Capital International Perspective Third Quarter 1994) and of the composition of our sample of individual stocks. The sample period is 1980:02-1999:06. The first subsample consists of the period 1980:02-1989:12. The second subsample is the period 1990:01-1999:06. Data on domestic and global market indices are obtained from MSCI

\begin{tabular}{|c|c|c|c|c|c|}
\hline Country & $\begin{array}{l}\text { Weight in MSCI } \\
\text { world index }\end{array}$ & $\begin{array}{l}\text { \# stocks in } \\
\text { sample }\end{array}$ & $\begin{array}{l}\text { Weight in } \\
\text { sample }\end{array}$ & $\begin{array}{l}\text { \# stocks in 1st } \\
\text { subsample }\end{array}$ & $\begin{array}{l}\text { \# stocks in } 2 \text { nd } \\
\text { subsample }\end{array}$ \\
\hline Australia & 2.3 & 108 & 3.3 & 118 & 244 \\
\hline Canada & 2.2 & 219 & 6.7 & 231 & 345 \\
\hline France & 3.7 & 127 & 3.9 & 130 & 500 \\
\hline Germany & 3.8 & 178 & 5.4 & 181 & 432 \\
\hline Japan & 28.7 & 829 & 25.2 & 734 & 1,755 \\
\hline Netherlands & 2.1 & 123 & 3.7 & 126 & 160 \\
\hline Switzerland & 2.7 & 129 & 3.9 & 136 & 264 \\
\hline United Kingdom & 9.4 & 1,051 & 31.9 & 1,118 & 1,245 \\
\hline United States & 35.6 & 529 & 16.1 & 557 & 749 \\
\hline Total & 90.5 & 3,293 & 100 & 3,331 & 5,694 \\
\hline
\end{tabular}


downloaded stock prices, dividend yields, and dividends of firms that are included in the Datastream equity lists. If dividends are unavailable, the dividend yield is used. If neither dividend data nor dividend yields are available, the stock is excluded from the sample. We also exclude stocks that have not been continuously listed over the whole period and stocks that are denominated in a currency different from the local currency of the country where they are listed. Furthermore, the data are filtered for data errors; stocks with outlier observations are excluded from the sample. ${ }^{9}$ Using stocks with a long time series history increases the power of our time series tests on regression coefficients. It also introduces survivorship bias that would invalidate a cross-sectional asset pricing test on the intercepts $\alpha_{i}$.

The second column of Table 2 reports the number of stocks included for each country after the selection procedures. The total sample consists of 3,293 stocks with a complete series of returns for the period 1980:02-1999:06. The third column of Table 2 shows the weight of each country in our world sample. The weight is computed by dividing the number of stocks in the country by the total number of stocks in the sample. Columns five and six of Table 2 show the number of stocks in our sample for two subperiods, 1980:02-1989:12 and 1990:01-1999:06. Tests on these additional stocks over the subsamples will help us to assess possible sample selection problems.

\section{Empirical results}

In this section, we discuss the main results we have obtained by applying the testing methodology introduced in Section 2 to the sample of 3,293 stocks. Throughout, we assume that the MSCI world and local indexes are good proxies for the global and local market portfolios, respectively. We apply the Pricing Error and Global Beta tests as discussed in Section 2 to each individual firm in order to assess the magnitude and significance of the pricing error made by the domestic CAPM as compared to the multifactor ICAPM. A summary of the test results is reported country-wise in Table 3 for the full sample period. All Wald tests in this paper are robust to heteroskedasticity.

Column 1 of Table 3 presents the rejection percentage of the Pricing Error test per country. That is, this column shows the percentage of stocks per country for which the CAPM yields a significant cost of capital differential with $95 \%$ confidence compared to the ICAPM. The hypothesis of a zero pricing error is rejected very infrequently for each country. The highest rejection percentage is 7.32 percent for the Netherlands, while the lowest is 3.10 percent for Switzerland. For the total sample of 3,293 firms, the Pricing Error test rejects in only 5.16 percent of the cases (170 companies). The fourth column of Table 3 shows the rejection percentage of the

9 These are stocks with average annual returns larger than $200 \%$, stocks with a local beta smaller than 0.1 , and infrequently traded stocks which have a zero return for more than twenty percent of the observations. 
Table 3

Pricing error test results

This table contains the rejection frequencies for two tests for each of the nine countries in our sample. The Pricing Error Test tests whether a pricing error exists between the domestic CAPM and the multifactor ICAPM using the regression $R_{i}=\alpha_{4 i}+R_{L} b_{i}+Z^{\prime}{ }_{\perp} p_{i}+v_{i}$. The Global Beta Test is similar to the Pricing Error Test but focuses on the beta error of the domestic CAPM versus the multifactor ICAPM, i.e. the first element of $p_{i}$. The asymptotic Wald tests are Chi-squared distributed and robust to heteroskedasticity. Rejection frequencies are defined as the percentage of firms in a country for which the null-hypothesis is rejected at the 5\% significance level. "Average" depicts a weighted average of the percentages of firms in each individual country for which the null-hypothesis is rejected. The weights of the rejection frequencies are the weights of each country in the sample as shown in the third column of Table 2 . The sample period is 1980:02-1999:06. This table also shows the rejection frequencies for both tests for two subsamples. The first subsample consists of the period 1980:02-1989:12. The second subsample is the period 1990:01-1999:06

\begin{tabular}{llllllll}
\hline \multirow{2}{*}{ Country } & \multicolumn{2}{c}{ Pricing Error Test (percentage rejections) } & \multicolumn{3}{c}{ Global Beta Test (percentage rejections) } \\
\cline { 2 - 3 } & $1980-1999$ & $1980-1989$ & $1990-1999$ & $1980-1999$ & $1980-1989$ & $1990-1999$ \\
\hline Australia & 4.63 & 4.24 & 2.87 & 1.85 & 4.24 & 9.02 \\
Canada & 4.11 & 3.46 & 3.77 & 6.85 & 6.93 & 8.41 \\
France & 5.51 & 1.54 & 2.20 & 4.72 & 6.15 & 9.20 \\
Germany & 6.74 & 3.87 & 2.55 & 2.25 & 4.42 & 3.01 \\
Japan & 5.79 & 2.73 & 3.82 & 3.98 & 9.54 & 7.18 \\
Netherlands & 7.32 & 0.79 & 1.88 & 4.88 & 4.76 & 6.25 \\
Switzerland & 3.10 & 7.35 & 3.41 & 0.78 & 10.29 & 1.89 \\
United Kingdom & 4.19 & 4.11 & 2.97 & 1.43 & 3.94 & 4.82 \\
United States & 6.05 & 3.95 & 4.94 & 2.84 & 4.85 & 5.87 \\
Average & 5.16 & 3.63 & 3.42 & 2.95 & 5.94 & 6.23 \\
\hline
\end{tabular}

Global Beta test per country. This test evaluates the significance of the first element of the pricing error vector $d_{L} b_{i}-d_{i}$. The total percentage of firms for which the hypothesis that the first element of this vector is equal to zero is rejected is 2.95 percent (97 firms). Individual countries such as Australia, the UK and the US show even lower percentages. Table 3 also displays rejection frequencies of the Pricing Error test and the Global Beta test for two subperiods. For the period 1980:021989:12, the Pricing Error test rejects for 3.63 percent of the 3,331 firms in the sample and the rejection frequency of the Global Beta test is equal to 5.95 percent. The hypothesis of no pricing error is rejected for 195 out of 5,694 companies in the subperiod 1990:01-1999:06. The Global Beta test rejects for 6.23 percent of the firms.

The evidence from Table 3 indicates that the domestic CAPM generally does not lead to a significantly different cost of capital than the multifactor ICAPM. On average, rejection of the null-hypothesis that this differential is equal to zero only occurs for about 5 percent of the firms in our sample. That is, the risk of a firm in our sample that is diversifiable locally does very rarely contain any additional systematic risk in the global market. As rejection frequencies for subperiods are very similar, 
we reckon that possible survivorship bias in our sample as well as the assumption that betas are not time-varying have little influence on our results.

In Table 4 we present rejection frequencies of the test for the null-hypothesis that no pricing error exists between the domestic CAPM and the single factor ICAPM (without currency risk factors) per country. The purpose of Table 4 is to show that our results do not critically depend on the version of the ICAPM we use as the benchmark model. ${ }^{10} \mathrm{We}$ reject the hypothesis that the CAPM leads to a significantly different estimate of the cost of capital than the single factor ICAPM for approximately 4 percent of the firms. Rejection percentages for subperiods are similar. The findings in Table 4 indicate that our pricing error results are not related to the addition of currency risk factors in the ICAPM. Several recent studies, e.g. Dumas and Solnik (1995) and De Santis and Gerard (1998), present evidence that exchange rate risk is priced for firms from a variety of countries. Even for the simple single factor version of the ICAPM excluding currency risk premia, however, we detect a very small number of rejections of the hypothesis that the pricing error is equal to zero.

Table 4

Pricing error test results for the single factor ICAPM

This table contains the rejection frequencies for the test of the null-hypothesis that no pricing error exists between the domestic CAPM and the single factor ICAPM using the regression $R_{i}=\alpha_{6 i}+R_{L} \varphi_{i}+$ $R_{G} \theta_{i}+w_{i}$. The null hypothesis is $\theta_{i}=0$. The asymptotic Wald test is Chi-squared distributed and robust to heteroskedasticity. Rejection frequencies are defined as the percentage of firms in a country for which the null-hypothesis is rejected at the 5\% significance level "Average" depicts a weighted average of the percentages of firms in each individual country for which the null-hypothesis is rejected. The weights of the rejection frequencies are the weights of each country in the sample as shown in the third column of Table 2. The sample period is 1980:02-1999:06, This table also shows the rejection frequencies for both tests for two subsamples. The first subsample consists of the period 1980:02-1989:12. The second subsample is the period 1990:01-1999:06

\begin{tabular}{llcc} 
Country & \multicolumn{2}{c}{ Pricing Error Test for the single factor ICAPM (percentage rejections) } \\
\cline { 2 - 4 } & $1980-1999$ & $1980-1989$ & $1990-1999$ \\
\hline Australia & 8.33 & 5.93 & 6.15 \\
Canada & 3.65 & 2.60 & 1.74 \\
France & 3.94 & 7.69 & 0.40 \\
Germany & 3.37 & 7.74 & 1.62 \\
Japan & 8.93 & 14.99 & 7.01 \\
Netherlands & 0.81 & 0.79 & 0.00 \\
Switzerland & 6.20 & 11.76 & 0.72 \\
United Kingdom & 2.57 & 4.11 & 0.67 \\
United States & 0.19 & 0.36 & 3.02 \\
Average & 4.22 & 6.36 & \\
\hline
\end{tabular}

${ }^{10}$ Note that exchange rate factors cannot be omitted from the multifactor ICAPM when PPP does not hold, even if exchange rate risk is not priced. Therefore, in general, exchange rate factors need to be included in the ICAPM. 
This suggests that the conclusion of Stulz (1995b) that the pricing error between the domestic CAPM and the single factor ICAPM is substantial for the Swiss multinational Nestlé does not generalize to a broad sample of companies.

Figure 1 provides an overview for the rejection frequencies of the three pricing error tests employed in this paper. The rejection frequencies exhibit remarkably little variation over both countries and testing methodologies. The figure substantiates our inference that the pricing error is very frequently statistically significant.

Figures 2 through 10 contain additional information on the pricing error tests for each country. The figures provide a scatter plot of each firm's "direct beta" versus its "indirect beta". The direct beta is the firm's multifactor ICAPM beta $d_{i 1}$, while the indirect estimate of a firm's global beta can be calculated by multiplying the global beta of the local market as represented by the first element of the vector $d_{L}$ and the firm's CAPM beta $b_{i}$. Summary statistics for the difference between the direct and the indirect beta are provided below the scatter plot. For each country, the dots in the graph are centered around the line with a slope of unity. ${ }^{11}$ For firms

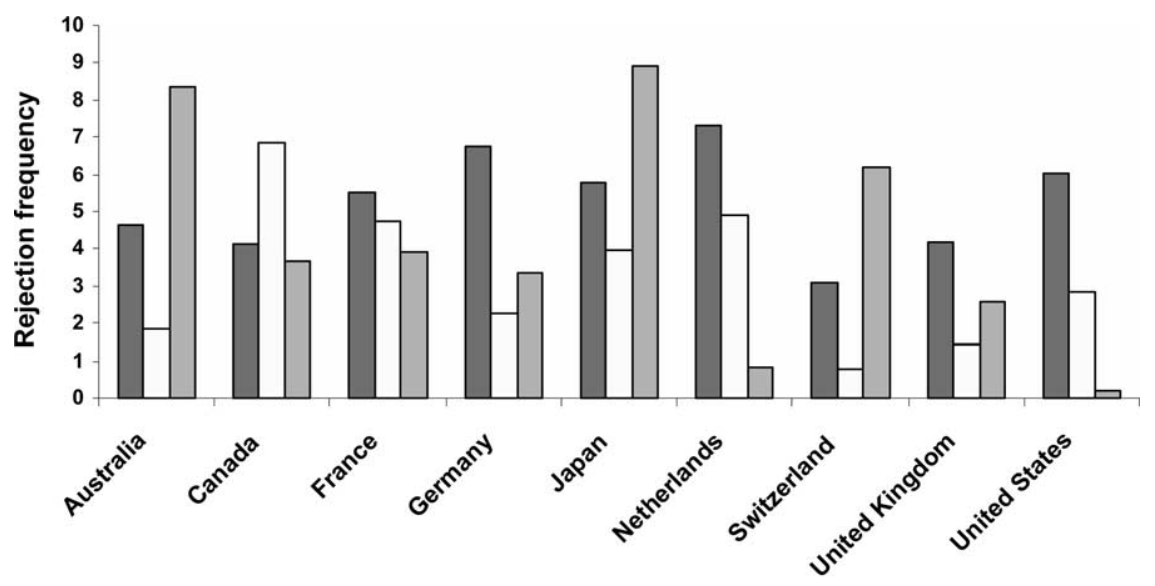

Pricing Error $\square$ Global Beta $\square$ Single Factor ICAPM

Fig. 1. Rejection frequencies of three pricing error tests. This figure depicts the rejection frequencies for the three pricing error tests for each of the nine countries in our sample. The pricing error test (column 1) tests whether a pricing error exists between the domestic CAPM and the multifactor ICAPM. The global beta test (column 2) examines the significance of the beta error of the domestic CAPM versus the multifactor ICAPM, i.e. the first element of $p_{i}$. The pricing error test for the single factor ICAPM (column 3) assesses whether a significant pricing error exists between the domestic CAPM and the single factor ICAPM. The asymptotic Wald tests are chi-squared distributed and robust to heteroskedasticity. Rejection frequencies are defined as the percentage of firms in a country for which the null-hypotheseis is rejected at the 5\% significance level. The sample period is 1980:02-1999:06.

\footnotetext{
${ }^{11}$ The value-weighted sum of the ICAPM betas equals unity. Also, each local market is priced correctly by the ICAPM, according to the internationally undiversifiable risks of that portfolio. By construction the market weighted average pricing error is equal to zero. This means that for an individual firm the CAPM and the ICAPM might give different cost of capital but on average, (value-weighted) domestic pricing provides the correct cost of capital. Note that the above characteristics only hold in a world where both
} 


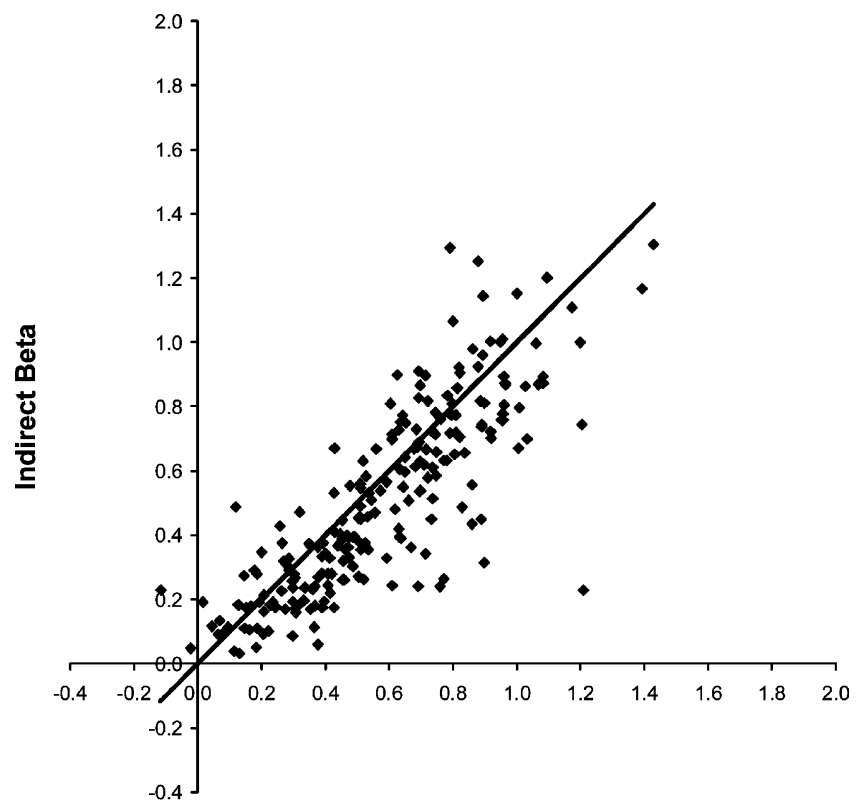

Direct Beta

Fig. 2. Australia: the cross-section of alternative beta estimates. This figure depicts a scatter plot of the "direct" ( $x$-axis) versus the "indirect" beta ( $y$-axis) for 108 companies. Direct betas are obtained from the multifactor IACPM and are equal to the OLS estimate of $d_{i 1}$ in the regression $R_{i}=\alpha_{1 i}+R_{G} d_{i 1}+$ $S^{\prime} d_{i 2}+u_{i}$. Indirect betas are calculated as the product of $b_{i}$ from the domestic CAPM $\left(R_{i}=\alpha_{2 i}+\right.$ $R_{L} b_{i}+e_{i}$ ) and the estimate of $d_{L 1}$ of the domestic market portfolio priced with the multifactor ICAPM, $R_{L}=\alpha_{L}+R_{G} d_{L 1}+S^{\prime} d_{L 2}+u_{L}$. The line in the graph reflects the $45^{\circ}$ line. The table at the bottom of the figure shows summary statistics of the difference between the direct and the indirect beta of all Australian firms. The columns present the mean, the mean of the absolute value, the standard deviation, the minimum and the maximum value of the beta errors, respectively. The sample period is 1980:021999:06. Data on domestic and global market indices are obtained from MSCI. Nominal exchange rates are taken from the International Financial Statistics (IFS) tape.

on this line, the estimated cost of capital is invariant to the use of the CAPM or ICAPM, if exchange rate risk is not priced. Firms that plot below the line have a higher cost of capital using the ICAPM than using the CAPM. The difference reflects a premium for risks that are diversifiable locally but not internationally. On the other hand, firms that lie above the line have a lower cost of capital according to the ICAPM as compared to the CAPM, suggesting the presence of non-diversifiable local risk that can be diversified internationally. Although for each country several firms plot off the straight line, the differences are generally small. ${ }^{12}$

local and global market indexes are measured perfectly including all individual stocks. In our empirical work, non-zero average pricing errors arise first because we do not use all stocks included in the local and global MSCI-indices, and second because we present equally weighted averages.

12 If exchange rate risk is priced, differences in the estimated cost of capital maybe larger because of differences in the directly and indirectly estimated coefficients on the exchange rate factors. 


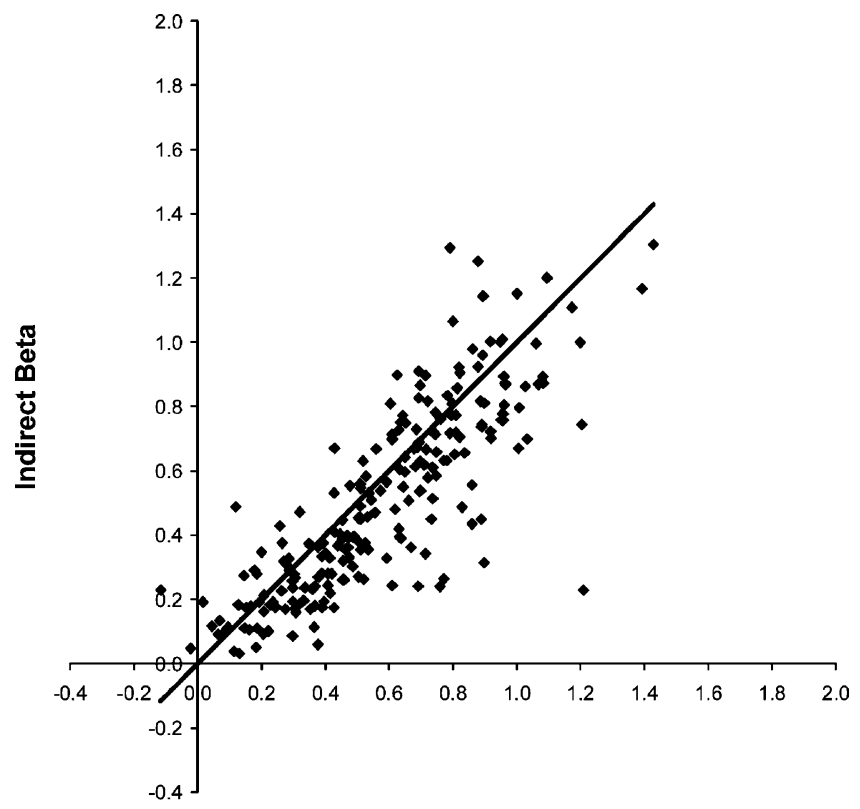

Direct Beta

Fig. 3. Canada: the cross-section of alternative beta estimates. This figure depicts a scatter plot of the "direct" ( $x$-axis) versus the "indirect" beta ( $y$-axis) for 219 companies. Direct and indirect beta estimates can be estimated as described in Fig. 1. The line in the graph reflects the $45^{\circ}$ line. The table at the bottom of the figure shows summary statistics of the difference between the direct and the indirect beta of all Canadian firms. The columns present the mean, the mean of the absolute value, the standard deviation, the minimum and the maximum value of the beta errors, respectively. The sample period is 1980:02-1999:06.

This is supported by the summary statistics. They show that the equally weighted average of the differences between the direct and the indirect betas is close to zero for all countries, as expected (see footnote 11). The absolute pricing error in terms of betas within each country is more interesting. This number varies from 0.076 (Germany and the US) to 0.123 (France) and is thus relatively small in beta terms. The (discrete) return on the global market portfolio over the sample period 1980 1999 was 15.2 percent annually when expressed in US dollars. Over the same period, the average one-month risk free rate was 7.8 percent, resulting in an excess market return of 7.4 percent. Consequently, the implied cost of capital difference between the two models amounts to 0.56 percent on average for US firms. ${ }^{13}$ For Germany the excess return on the global market in local currency equals 9.4 percent, yielding a pricing error in terms of cost of capital of 0.71 percent. For Japan the implied cost of capital differential is equal to 0.78 percent, while for France the difference is equal to 1.01 percent per year in local currency.

\footnotetext{
${ }^{13}$ In the absence of currency risk premia (and in the absence of deviations from the restriction $\left.\alpha_{1 i}=\alpha_{2 i}+b_{i} \alpha_{L}\right)$ the difference $\left(d_{L} b_{i}-d_{i}\right) E\left[R_{G}-r_{0}\right]$ would give an estimate of the cost of capital difference between the domestic and the international CAPM.
} 


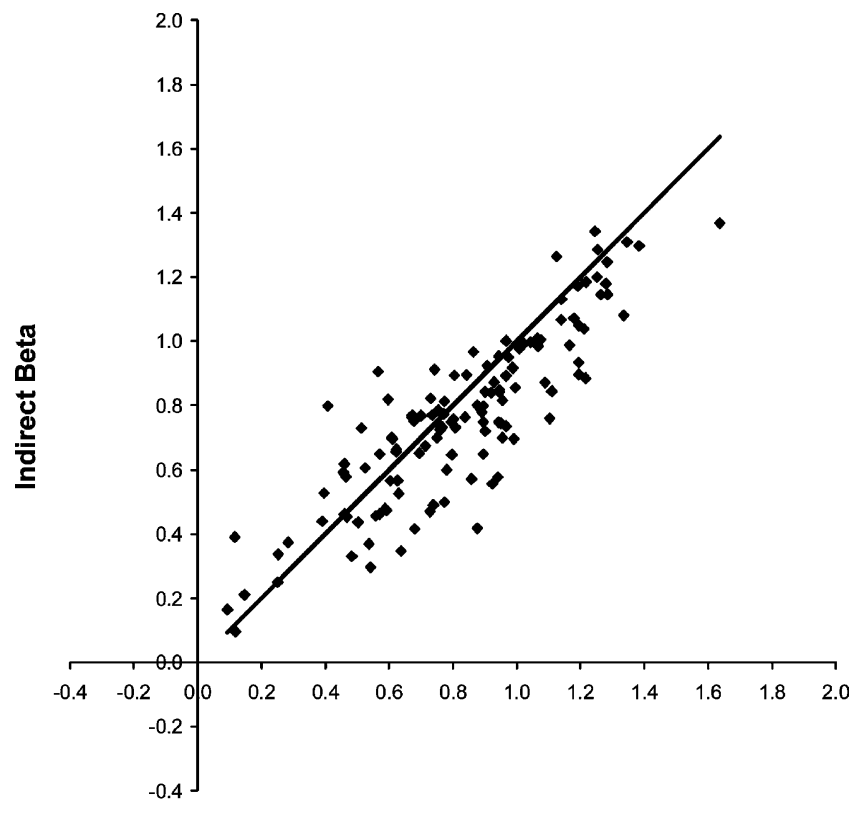

Direct Beta

Fig. 4. France: the cross-section of alternative beta estimates. This figure depicts a scatter plot of the "direct" ( $x$-axis) versus the "indirect" beta ( $y$-axis) for 127 companies. Direct and indirect beta estimates can be estimated as described in Fig. 1. The line in the graph reflects the $45^{\circ}$ line. The table at the bottom of the figure shows summary statistics of the difference between the direct and the indirect beta of all French firms. The columns present the mean, the mean of the absolute value, the standard deviation, the minimum and the maximum value of the beta errors, respectively. The sample period is 1980:02-1999:06.

Figures 2 through 10 show that the pricing error in terms of beta is not only not statistically significant but also small in economic terms. Most firms plot close to the line with a slope of unity in the scatter plots. The summary statistics show that the average of the absolute differences between the betas estimated by the CAPM and the multifactor ICAPM is relatively small for all countries. In cost of capital terms, these differences generally amount to less than one percent.

\section{Local, global and currency factors: a variance decomposition}

This section further explores our finding that the pricing error is rarely statistically significant in our sample of almost 3,300 international stocks. We investigate how much of the risk that is specific from a local country perspective is systematic from a global perspective. For this we use a variance decomposition metric that allows for an assessment of the respective contributions of the local market, the global market and the vector of exchange rate changes to an individual asset $i$ 's return.

The decomposition starts from the domestic CAPM and investigates how much global market and currency factors add to the local market index as a measure of 


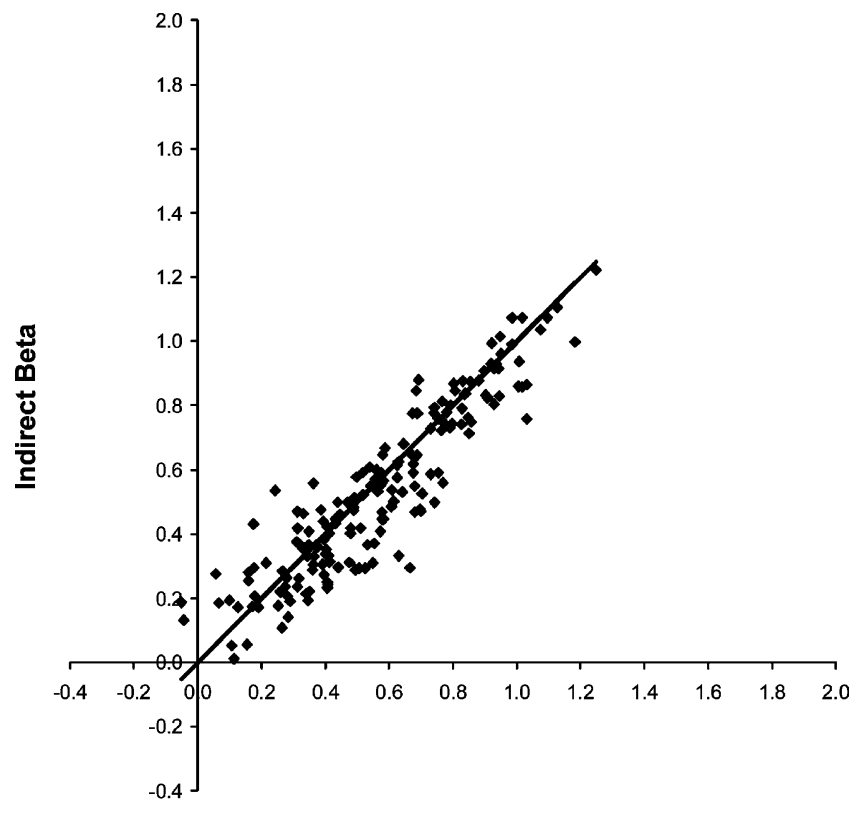

Direct Beta

Fig. 5. Germany: the cross-section of alternative beta estimates. This figure depicts a scatter plot of the "direct" ( $x$-axis) versus the "indirect" beta ( $y$-axis) for 178 companies. Direct and indirect beta estimates can be estimated as described in Fig. 1. The line in the graph reflects the $45^{\circ}$ line. The table at the bottom of the figure shows summary statistics of the difference between the direct and the indirect beta of all German firms. The columns present the mean, the mean of the absolute value, the standard deviation, the minimum and the maximum value of the beta errors, respectively. The sample period is 1980:02-1999:06.

systematic risk. We consider the regression model (9) with the local market index $R_{L}$ and the orthogonalized global factors $Z_{\perp}$. Taking the variance of both the left and the right hand side of eq. (9), Appendix A shows that the variance of stock $i$ can be expressed as

$$
\omega_{i}^{2}=b_{i}^{2} \omega_{L}^{2}+p^{\prime}{ }_{i} \Omega+\left(\frac{\Omega d_{L} d^{\prime}{ }_{L} \Omega}{\sigma_{L}^{2}}\right) p_{i}+\sigma_{i}^{2} .
$$

In eq. (10) the total variance of stock $i$ (denoted by $\omega_{i}^{2}$ ) is decomposed into systematic local market risk (related to the variance $\omega_{L}^{2}$ of the local market return), additional global risk in $Z$ that is orthogonal to the local market (related to the covariance matrix $\Omega$ of $Z$ ) and specific risk $\sigma_{i}^{2}$. Note that the contribution of the global factors should be zero under the null hypothesis that the domestic CAPM does not yield a different cost of capital than the multifactor ICAPM, i.e., when $p_{i}=0$.

In Fig. 11, the average variance decomposition according to eq. (10) is given for each country. The figure provides information on the explanatory power of the local and the orthogonalized global factors in a regression of individual stock returns. From the graph, it is clear that the marginal contribution of the global factors $Z$ across firms in one country is negligible on average. Obviously, the choice between 


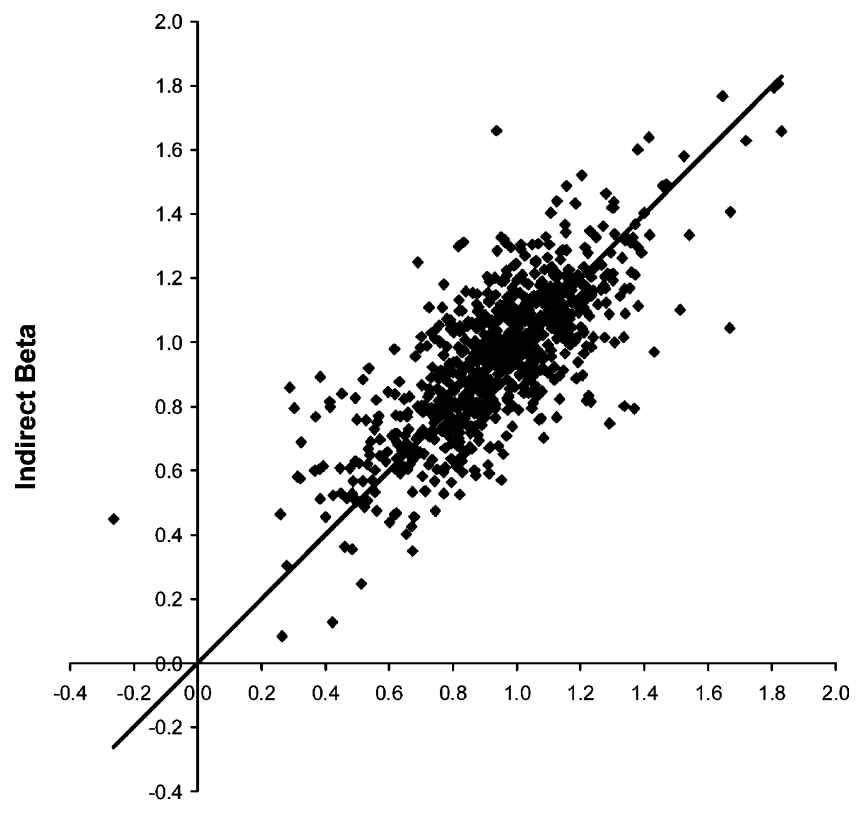

Direct Beta

Fig. 6. Japan: the cross-section of alternative beta estimates. This figure depicts a scatter plot of the "direct" ( $x$-axis) versus the "indirect" beta ( $y$-axis) for 829 companies. Direct and indirect beta estimates can be estimated as described in Fig. 1 . The line in the graph reflects the $45^{\circ}$ line. The table at the bottom of the figure shows summary statistics of the difference between the direct and the indirect beta of all Japanese firms. The columns present the mean, the mean of the absolute value, the standard deviation, the minimum and the maximum value of the beta errors, respectively. The sample period is 1980:02-1999:06.

domestic CAPM and the multifactor ICAPM does not matter a great deal for the computation of the cost of capital. ${ }^{14}$ Our results provide support for the existence of important country effects in asset pricing, consistent with De Ménil (1999); Heston and Rouwenhorst (1994); Rouwenhorst (1999); Griffin and Karolyi (1998), and Griffin (2001), who show that the cross-section of returns and their variations across international equity markets are caused by large country-specific components, and not industrial structure.

Figure 11 suggests that most firms within one country share a common exposure to international currency and stock market factors. Since such average exposure is captured in the international pricing of the local stock market index, this index in turn is a sufficient statistic against which to measure an individual firm's sensitivity to global factors. This means that even in integrated markets the pricing error is very small for most firms, because the local market factor can serve as a proxy for the

\footnotetext{
${ }^{14}$ The extent to which formal rejection of a pricing error is possible, can be shown to depend on the overall explanatory power of the ICAPM. In other words, the power of the test depends on the performance of the model. Unreported results are available from the authors to illustrate this point.
} 


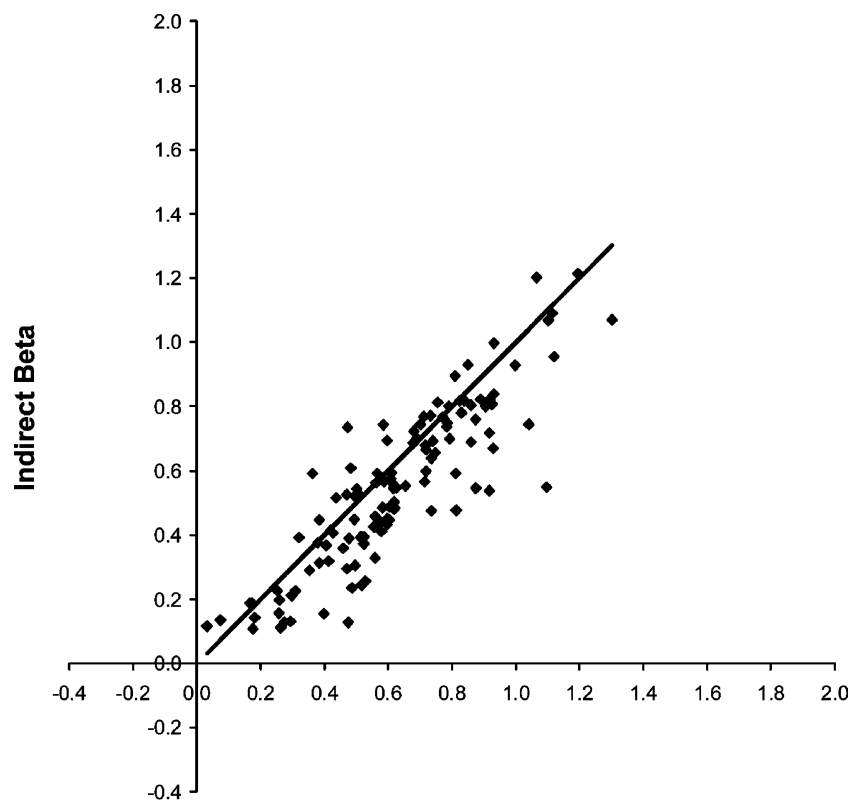

Direct Beta

Fig. 7. The Netherlands: the cross-section of alternative beta estimates. This figure depicts a scatter plot of the "direct" ( $x$-axis) versus the "indirect" beta ( $y$-axis) for 123 companies. Direct and indirect beta estimates can be estimated as described in Fig. 1. The line in the graph reflects the $45^{\circ}$ line. The table at the bottom of the figure shows summary statistics of the difference between the direct and the indirect beta of all Dutch firms. The columns present the mean, the mean of the absolute value, the standard deviation, the minimum and the maximum value of the beta errors, respectively. The sample period is 1980:02-1999:06.

omitted global factors in the domestic CAPM. The domestic CAPM induces a pricing error only for firms that have significantly deviating exposure from the local market. Obviously, our exposure results are consistent with the pricing error test results in Tables 3 and 4 .

Both sets of results point to the fact that a firm's risk profile is closely connected to the country from which it operates. This holds for the large majority of firms. A tentative explanation of this finding is related to what De Ménil (1999) calls lack of real capital market integration. De Ménil (1999) finds that both cyclical and structural, and institutional country-specific factors significantly contribute to the explanation of cross-country differences in ROA for large non-financial firms. More in particular, he finds significant effects for the level of capital deepening and for the regulatory environment. With respect to the latter, De Ménil points to labor market regulation and product market regulation as significant determinants of firm performance. Clearly, all firms within the same national jurisdiction face similar constraints and opportunities in this respect. Similarly, Koedijk and Kremers (1996) show that differences in medium-term macroeconomic growth across the European Union are negatively related to market regulation. In short, with a lack of real capital market 


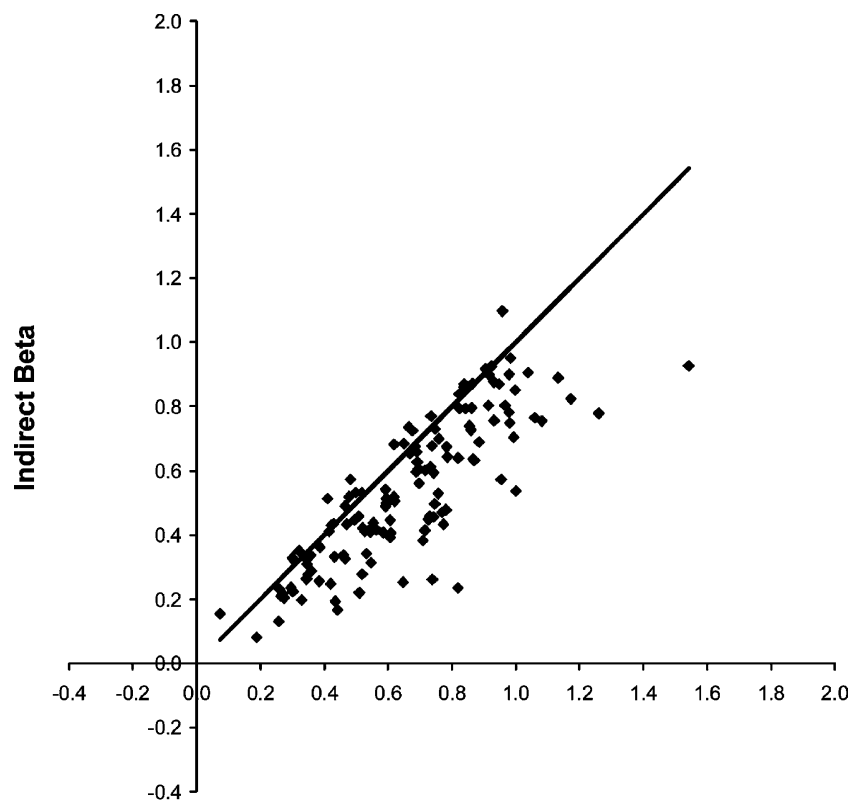

Direct Beta

Fig. 8. Switzerland: the cross-section of alternative beta estimates. This figure depicts a scatter plot of the "direct" ( $x$-axis) versus the "indirect" beta ( $y$-axis) for 129 companies. Direct and indirect beta estimates can be estimated as described in Fig. 1. The line in the graph reflects the $45^{\circ}$ line. The table at the bottom of the figure shows summary statistics of the difference between the direct and the indirect beta of all Swiss firms. The columns present the mean, the mean of the absolute value, the standard deviation, the minimum and the maximum value of the beta errors, respectively. The sample period is 1980:02-1999:06.

integration and substantial cross-country differences in market regulation, a country's fortunes and the fortunes of the firms operating in this country are closely tied together. It may be true that certain firm characteristics such as size and degree of international activities play a role in explaining the deviating exposure of a firm relative to the local market. Further research is required to examine this issue.

Increasing harmonization of regulatory policies as is happening in the EU will reduce these structural differences. In the same vein, increasing real integration will reduce cyclical differences. For the time being, substantial differences remain between countries and firms across countries. These differences can and should be used by individual investors for the purpose of portfolio diversification. Note that the lack of real integration is separate from the issue of financial integration. Because we take the ICAPM as the null, we assume that markets are well integrated. Consequently, our results have no implication for the integration of global financial markets. Rather, these markets should be used to diversify across countries. Diversification across industries within one country is insufficient to cope with a country's systematic risk according to our results. In that sense, our evidence reinforces the home bias puzzle. 


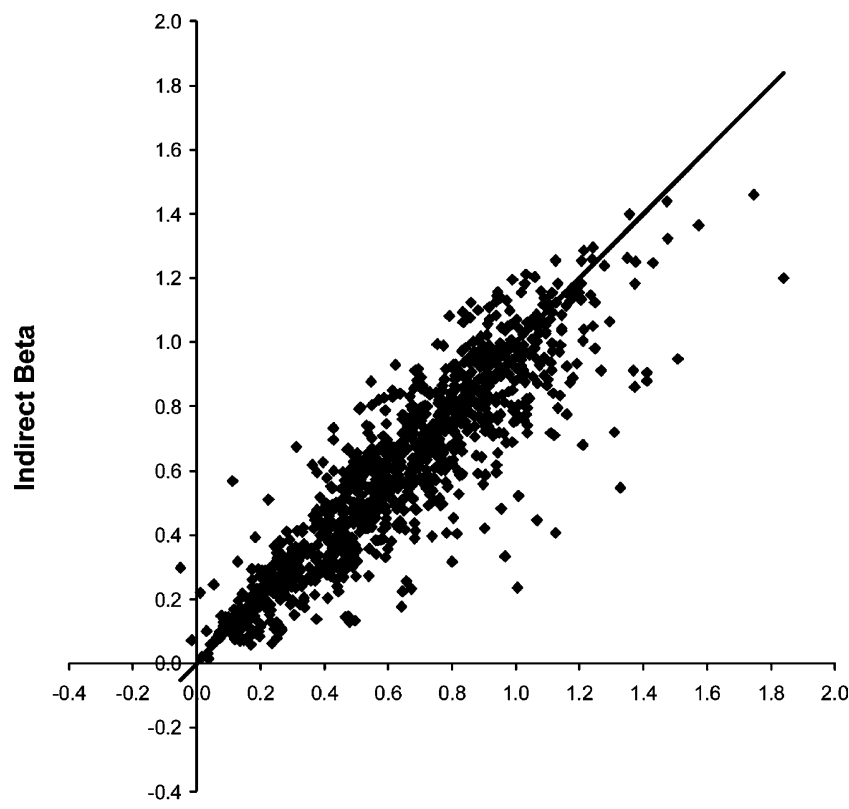

Direct Beta

Fig. 9. United Kingdom: the cross-section of alternative beta estimates. This figure depicts a scatter plot of the "direct" ( $x$-axis) versus the "indirect" beta ( $y$-axis) for 1,051 companies. Direct and indirect beta estimates can be estimated as described in Fig. 1. The line in the graph reflects the $45^{\circ}$ line. The table at the bottom of the figure shows summary statistics of the difference between the direct and the indirect beta of all UK firms. The columns present the mean, the mean of the absolute value, the standard deviation, the minimum and the maximum value of the beta errors, respectively. The sample period is 1980:021999:06.

\section{Foreign exchange exposure}

In Section 2 we showed that in general testing for a pricing error can be implemented by examining the statistical significance of a set of instrumental variables in a time series regression of the stock return of an individual firm on an intercept and the domestic market return (see eq. (8)). These pricing error tests are very similar to the well-known tests for exchange rate exposure. In this section, we perform several exchange rate exposure tests and show that the results of Section 5 can shed light on the well-known puzzle that companies show hardly any exposure to exchange rate fluctuations.

Adler and Dumas (1984) define foreign exchange exposure as the impact of exchange rate movements on the value of a firm. Recent papers in the field, e.g. Jorion (1990); Bartov and Bodnar (1994), and He and Ng (1998) test for currency exposure of individual companies using a version of the time series regression

$$
R_{i}=\gamma_{0 i}+R_{L} \gamma_{1 i}+f(S)^{\prime} \gamma_{2 i}+\varepsilon_{i}
$$

where $f(S)$ is a function of the nominal exchange rate returns expressed in the home 


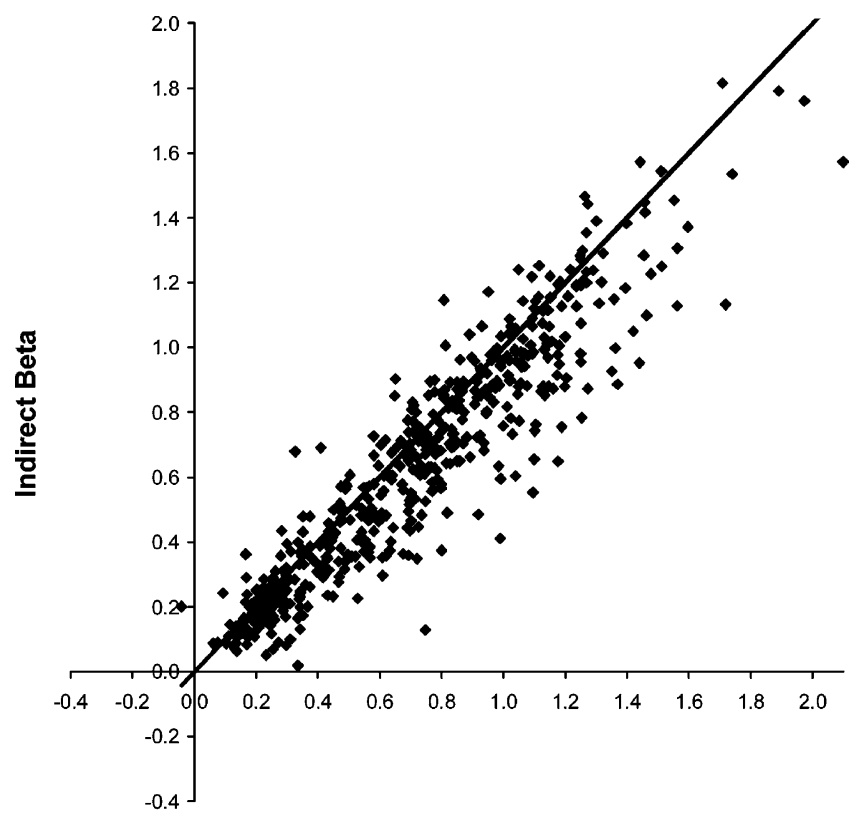

Direct Beta

Fig. 10. United States: the cross-section of alternative beta estimates. This figure depicts a scatter plot of the "direct" ( $x$-axis) versus the "indirect" beta ( $y$-axis) for 529 companies. Direct and indirect beta estimates can be estimated as described in Fig. 1. The line in the graph reflects the $45^{\circ}$ line. The table at the bottom of the figure shows summary statistics of the difference between the direct and the indirect beta of all US firms. The columns present the mean, the mean of the absolute value, the standard deviation, the minimum and the maximum value of the beta errors, respectively. The sample period is 1980:021999:06.

currency of firm $i$. The null-hypothesis of the test for currency exposure can be formulated as $\mathrm{H}_{0}: \gamma_{2 i}=0$. This test can also be interpreted as a pricing error test as it analyzes whether any systematic (currency) risk can be filtered out from the risk of a firm that is diversifiable domestically.

Several versions of regression (12) have been used in the literature. Most studies use a trade-weighted exchange rate index for $f(S)$. An alternative would be to define $f(\bullet)$ to be a linear projection. In this paper, the latter test is called the "Exposure" test. It uses a subset of the orthogonality conditions in eq. (8).

We suspect that foreign currency exposure as estimated in eq. (12) may (in part) be captured by the domestic market factor. In order to control for this effect we also run the alternative regression

$$
R_{i}=c_{0 i}+S^{\prime} c_{1 i}+\eta_{G} c_{2 i}+\eta_{L} c_{3 i}+v_{i}
$$

where $\eta_{G}$ is the residual vector from regressing $R_{G}$ on an intercept and $S$. Similarly, $\eta_{L}$ is the residual vector from regressing $R_{L}$ on an intercept, $R_{G}$ and $S$. By orthogonalizing $R_{L}$, we want to accomplish that the coefficient on $S$ does not merely reflect 


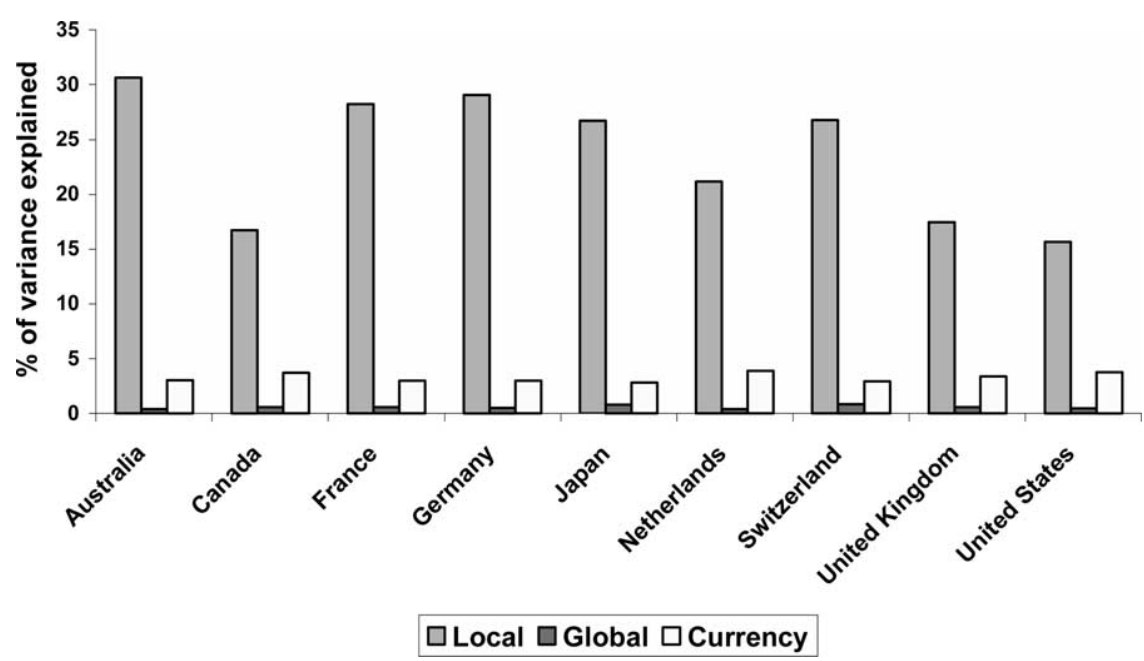

Fig. 11. Average pricing error decomposition. This figure presents the variance decomposition described in Section 5. The general idea behind this decomposition is that the orthoganalized global market factor and the currency risk factors are added to the CAPM regression $R_{i}=\alpha_{4 i}+R_{L} b_{i}+Z^{\prime}{ }_{\lrcorner} p_{i}+v_{i}$, where $Z_{\perp}=Z-u_{L} \gamma_{L}^{\prime}$, and $\gamma_{L}=\Omega d_{L} / \sigma_{L}^{2}$. The regressors $Z_{\perp}$ are orthogonal to $R_{L}$ and the parameters $p_{i}$ can be directly interpreted as the pricing errors. Note that $d_{L}, \Omega$ and $\sigma_{L}^{2}$ are unrelated to asset $i$ and are treated as exogenous. The variance due to the domestic factor is $\omega_{L}^{2} b_{i}^{2}$, while the marginal variance attributed to the global factor is $p_{i}^{\prime} E\left[Z_{\perp} Z^{\prime}{ }_{\perp}\right] p_{i}=p_{i}^{\prime}\left\{\Omega+\left[\left(\Omega d_{L} d^{\prime}{ }_{L} \Omega\right) / \sigma_{L}^{2}\right]\right\} p_{i}$. With this metric we are able to estimate to what extent the global market and the exchange rate risk factors add explanatory power to the domestic CAPM. Under the null-hypothesis of no pricing error the global factors should have no contribution to the total variance. The variance decomposition for a country is equal to the weighted average of all decompositions of individual firms in that country with $\left(1 / \sigma_{i}^{2}\right) /\left(\Sigma 1 / \sigma_{i}^{2}\right)$ as weights. The vertical axis depicts the explanatory power of each of the factors in terms of the percentage of the total variance of a stock which can be explained by that factor. The sample period is 1980:02-1999:06.

the deviating exposure of firm $i$ from the average currency exposure of all firms in the country. The test of $c_{1 i}=0$ is called the "Total Exposure" test.

An alternative way to estimate exchange rate exposure is in a regression of a stock return on the global market return and exchange rate returns. It is unlikely that most of the joint currency exposure would also be captured by the global stock market, which contains a much more diverse population of firms. The appropriate regression to run is the following:

$$
R_{i}=\alpha_{1 i}+R_{G} d_{i 1}+S^{\prime} d_{i 2}+u_{i} .
$$

Note that eq. (13) is the same as eq. (2). This regression looks for significant "Currency Betas". A short description of the hypotheses underlying the Total Exposure and the Currency Betas tests is presented in Table 1.

The first column of Table 5 depicts the percentage of firms in each individual country for which the null-hypothesis of no currency exposure is rejected at the $95 \%$ confidence level. Several recent studies, e.g. Bartov and Bodnar (1994), and He and $\mathrm{Ng}$ (1998) report results that are consistent with the exchange rate exposure puzzle. Consistent with the literature, we find that significant exposure exists on average for 


\section{Table 5}

Foreign exchange rate exposure tests

This table presents rejection frequencies for three tests for each of the nine countries in our sample. The Exposure Test tests for foreign exchange rate exposure of individual stocks when controlled for the local market index. The Total Exposure Test tests for exchange rate exposure when controlled for fluctuations in the local market index that are orthogonal to all exchange rates. The Currency Betas Test tests for exposure of individual firms when the global market return is included in the regression. The asymptotic Wald tests are Chi-squared distributed and robust to heteroskedasticity. Rejection frequencies are defined as the percentage of firms in a country for which the null-hypothesis is rejected at the 5\% significance level. "Average" depicts a weighted average of the percentages of firms in each individual country for which the null-hypothesis is rejected. The weights of the rejection frequencies are the weights of each country in the sample as shown in the third column of Table 2. The sample period is 1980:02-1999:06. Data on domestic and global market indices are obtained from MSCI. Data on individual stocks are obtained from the Datastream equity lists. Nominal exchange rates are taken from the International Financial Statistics (IFS) tape. Stocks with incomplete price or dividend data, stocks with outlier observation and illiquid stocks have been removed from the dataset.

\begin{tabular}{llll}
\hline Country & $\begin{array}{l}\text { Exposure Test } \\
\text { (percentage rejections) }\end{array}$ & $\begin{array}{l}\text { Total Exposure Test } \\
\text { (percentage rejections) }\end{array}$ & $\begin{array}{l}\text { Currency Betas Test } \\
\text { (percentage rejections) }\end{array}$ \\
\hline Australia & 12.04 & 74.07 & 74.07 \\
Canada & 12.79 & 47.03 & 51.14 \\
France & 14.96 & 50.39 & 46.46 \\
Germany & 20.22 & 48.88 & 46.07 \\
Japan & 16.16 & 52.47 & 73.22 \\
Netherlands & 17.07 & 53.66 & 20.33 \\
Switzerland & 6.98 & 57.36 & 34.88 \\
United Kingdom & 11.23 & 36.44 & 27.02 \\
United States & 14.74 & 38.56 & 45.70 \\
Average & 13.85 & 45.43 & 45.67 \\
\hline
\end{tabular}

about 14 percent of the firms in our sample. As mentioned in Section 5, the variance decomposition in Fig. 11 shows that most firms within a country have a joint exposure to the global market and exchange rates. Therefore, the evidence in column 1 of Table 5 does not necessarily imply that the value of a firm is not affected by changes in exchange rates. The exposure may at least partly be captured by the domestic market factor.

The rejection percentages for the Total Exposure test as depicted in column 2 of Table 5 are considerably higher than those of the Exposure test. On average about 45 percent of the firms exhibit significant currency exposure. The highest rejection percentage is 74.07 percent for Australia, while the lowest is 36.44 percent for the UK, The results for the Currency Betas test are very similar to these findings. ${ }^{15}$ This corroborates our results.

\footnotetext{
15 Test results for subperiods are qualitatively similar. They are not reported in this paper but are available from the authors on request.
} 


\section{Conclusions}

While theory suggests the use of an international CAPM in integrated capital markets, the domestic CAPM does not necessarily imply an incorrect estimate of the cost of capital. In this paper, we examine to what extent international and domestic asset pricing models imply a different estimate of the cost of capital for a sample of monthly data for 3,293 firms from nine major industrialized countries from 1980 to 1999 . We distinguish between: (i) the multifactor ICAPM of Solnik-Sercu including both the global market portfolio and exchange rate risk premia, and (ii) the single factor domestic CAPM. Our analysis allows for an assessment of what is important in cost of capital computations and what is not.

The main results of this paper stem from two time series regressions we run for each individual stock in the sample. First, when we run a regression of the return on an individual stock on the return on the world market index and several exchange rates, we find that a large number of companies are exposed to fluctuations in exchange rates. Foreign exchange exposure is statistically significant for more than 45 percent of the firms in our sample. Second, when we incorporate the domestic market index in this regression, the exposure to exchange rates dissolves for most firms. In fact, both the global market index and the exchange rate factors become insignificant for the vast majority of corporations. The global factors are jointly significant for only approximately 5 percent of the firms in our sample.

We draw the following conclusions from this analysis. Firms are exposed to global risk factors, validating an international finance approach to measuring the cost of equity capital. Corporations within a country by and large exhibit a joint exposure to international risk factors. For a large majority of companies, this joint exposure is folly captured in the international pricing of the domestic market index. That is, stock returns are generally dominated by an index of their local currency domestic market index. This finding is corroborated by a variance decomposition analysis. As a result, the systematic risk of a stock implied by the single factor domestic CAPM is very infrequently significantly different from the systematic risk implied by the multifactor ICAPM. The implied cost of capital differential is also small in economic terms. The difference in the estimate of a firm's systematic risk amounts to around 50 basis points on average for the US, roughly 75 basis points for Germany and Japan, and approximately 100 basis points for France. Independent of the issue whether international capital markets are fully integrated, the domestic CAPM rarely leads to a different estimate of the cost of capital than the multifactor ICAPM. A tentative explanation of this finding is a lack of real capital market integration, due to both cyclical and structural, and institutional country-specific factors. Furthermore, our evidence reinforces the home bias puzzle. Further research is required to examine these issues.

\section{Acknowledgements}

We thank Geert Bekaert, Frans de Roon, Casper de Vries, Bernard Dumas, Alex Lammertsma, Jim Lothian (the editor), Kate Phylaktis (the referee), Piet Sercu, René 
Stulz, Jean-Pierre Urbain, Tom Vinaimont, and seminar participants at Indiana University (Bloomington), Washington University (St. Louis), Catholic University of Louvain, University of Amsterdam, the Federal Reserve Bank of St. Louis, the 1999 Econometric Society European Meeting in Santiago de Compostela, the 1999 European Finance Association Meetings in Helsinki, the 1999 CEPR Meeting on Capital Markets in Louvain-la-Neuve, the 2000 American Finance Association Meetings in Boston, and the 2001 X International "Tor Vergata" Conference on Banking and Finance in Rome for helpful discussion and comments on previous versions of this paper. We are solely responsible for any remaining errors.

\section{Appendix A}

In this appendix we show that the pricing error of the CAPM as compared to the multifactor ICAPM can be expressed as a linear combination of the parameter $\delta_{i}$ in regression (8) in the text,

$$
R_{i}=\alpha_{4 i}+R_{L} \beta_{i}+Z^{\prime} \delta_{i}+v_{i}
$$

The moment conditions of eq. (A1) can be written as

$$
\left(\begin{array}{ll}
\omega_{L}^{2} & d^{\prime}{ }_{L} \Omega \\
\Omega d_{L} & \Omega
\end{array}\right)\left(\begin{array}{l}
\beta_{i} \\
\delta_{i}
\end{array}\right)=\left(\begin{array}{l}
\omega_{L}^{2} b_{i} \\
\Omega d_{i}
\end{array}\right)
$$

where $\Omega$ is the $(N+1) \times(N+1)$ covariance matrix of $Z ; \omega_{L}^{2}$ is the variance of $R_{L} ; d_{L}$ is the vector of regression parameters in the ICAPM regression,

$$
R_{L}=\alpha_{L}+Z^{\prime} d_{L}+u_{L}
$$

for the local market portfolio; and $b_{i}=\operatorname{Cov}\left(R_{l}, R_{L}\right) / \operatorname{Var}\left(R_{L}\right)$ is the local market beta. The covariance between $Z$ and $R_{L}$ is therefore equal to $\Omega d_{L}$. Similarly the covariance between $R_{i}$ and $R_{L}$ is $\omega_{L}^{2} b_{i}$. Solving for $\delta_{i}$ from the second line of (A2) we get

$$
\delta_{i}=d_{i}-d_{L} \beta_{i}
$$

Substituting this expression into the first line of eq. (A2) gives

$$
\beta_{i}=\frac{\omega_{L}^{2} b_{i}-d^{\prime}{ }_{L} \Omega d_{i}}{\omega_{L}^{2}-d^{\prime}{ }_{L} \Omega d_{L}}=b_{i}-\frac{d^{\prime}{ }_{L} \Omega p_{i}}{\sigma_{L}^{2}},
$$

where $p_{i}=d_{L} b_{i}-d_{i}$ is the pricing error and $\sigma_{L}^{2}$ is the variance of residuals $u_{L}$ in equation (A3). Substituting this expression for $\beta_{i}$ back into eq. (A4) yields

$$
\delta_{i}=\left(1+\frac{d_{L} d^{\prime}{ }_{L} \Omega}{\sigma_{L}^{2}}\right) p_{i}
$$

From the interpretation of $\beta_{i}$ and $\delta_{i}$ it follows that a more insightful reparameterization of (8) in the text is

$$
R_{i}=\alpha_{4 i}+R_{L}\left(b_{i}-\frac{d^{\prime}{ }_{L} \Omega p_{i}}{\sigma_{L}^{2}}\right)+Z^{\prime}\left(I+\frac{d_{L} d^{\prime}{ }_{L} \Omega}{\sigma_{L}^{2}}\right) p_{i}+v_{i}
$$




$$
=\alpha_{4 i}+R_{L} b_{i}+Z^{\prime}{ }_{\perp} p_{i}+v_{i},
$$

where $Z_{\perp}=Z-u_{L} \gamma_{L}^{\prime}$, and $\gamma_{L}=\Omega d_{L} / \sigma_{L}^{2}$. The new regressors $Z_{\perp}$ are orthogonal to $R_{L}$ and the parameters $p_{i}$ can be directly interpreted as the pricing errors. Note that $d_{L}, \Omega$, and $\sigma_{L}^{2}$ are unrelated to asset $i$ and are treated as exogenous. Equation (A7) is also used for the variance decomposition in Section 5. The variance due to the domestic factor is $\omega_{L}^{2} b_{i}^{2}$, while the marginal variance attributed to the global factors is

$$
p^{\prime}{ }_{i} \mathrm{E}\left[Z_{\perp} Z^{\prime}{ }_{\perp}\right] p_{i}=p^{\prime}{ }_{i}\left(\Omega+\frac{\Omega d_{L} d^{\prime}{ }_{L} \Omega}{\sigma_{L}^{2}}\right) p_{i} \text {. }
$$

Equation (A8) shows the additional variance explained by the global factors. Equation (10) in the text follows directly from (A7) and (A8) and the orthogonality of $R_{L}$ and $Z_{\perp}$.

\section{References}

Abuaf, N., Jorion, P., 1990. Purchasing power parity in the long run. Journal of Finance 45, 157-174.

Adler, M., Dumas, B., 1983. International portfolio choice and corporation finance: a synthesis. Journal of Finance 38, 925-984.

Adler, M., Dumas, B., 1984. Exposure to currency risk: definition and measurement. Financial Management $13,41-50$.

Amihud, Y., 1994. Evidence on exchange rates and valuation of equity shares. In: Amihud, Y., Levich, R.M. (Eds.), Exchange Rates and Corporate Performance. Irwin, New York.

Bartov, E., Bodnar, G.M., 1994. Firm valuation, earnings expectations, and the exchange-rate exposure effect. Journal of Finance 49, 1755-1785.

Bodnar, G.M., Gentry, W.M., 1993. exchange rate exposure and industry characteristics: evidence from Canada, Japan, and the USA. Journal of International Money and Finance 12, 29-45.

De Ménil, G., 1999. Real capital market integration in the EU: how far has it gone? What will the effect of the Euro be? (with discussion). Economic Policy 28, 167-204.

De Santis, G., Gérard, B., 1998. How big is the premium for currency risk? Journal of Financial Economics 49, 375-412.

Dumas, B., Solnik, B., 1995. The world price of exchange rate risk. Journal of Finance 50, 445-479.

Engel, C., 1996. The forward discount anomaly and the risk premium: a survey of recent evidence. Journal of Empirical Finance 3, 123-191.

Fama, E.F., French, K.R., 1998. Value versus growth: the international evidence. Journal of Finance 53, 1975-1999.

Ferson, W.E., Harvey, C.R., 1993. The risk and predictability of international equity returns. Review of Financial Studies 6, 527-566.

Frankel, J.A., Rose, A.K., 1996. A panel project on purchasing power parity: mean reversion within and between countries. Journal of International Economics 40, 209-224.

Grauer, F.L., Litzenberger, R.H., Stehle, R.E., 1976. Sharing rules and equilibrium in an international capital market under uncertainty. Journal of Financial Economics 3, 233-256.

Griffin, J.M., 2001. Are the Fama and French factors global or country-specific? Review of Financial Studies, (in press).

Griffin, J.M., Karolyi, G.A., 1998. Another look at the role of the industrial structure of markets for international diversification strategies. Journal of Financial Economics 50, 351-373.

Harvey, C.R., 1991. The world price of covariance risk. Journal of Finance 46, 111-157.

He, J., Ng, L.K., 1998. The foreign exchange exposure of Japanese multinational corporations. Journal of Finance 53, 733-753. 
Heston, S.L., Rouwenhorst, K.G., 1994. Does industrial structure explain the benefits of international diversification? Journal of Financial Economics 36, 3-27.

Jorion, P., 1990. The exchange-rate exposure of US multinationals. Journal of Business 63, 331-345.

Karolyi, A.G., Stulz, R.M., 2002. Are financial assets priced locally or globally? Ohio State University working paper, forthcoming (2003) in: G. Constantinides, M. Harris, and R. M. Stulz (eds.), Handbook of the Economics of Finance, North-Holland.

Keck, T., Levengood, E., Longfield, A., 1998. Using discounted cash flow analysis in an international setting: a survey of issues in modeling the cost of capital. Journal of Applied Corporate Finance 3, 82-99.

Koedijk, C.G., Kremers, J., 1996. Market opening, regulation, and growth (with discussion). Economic Policy 23, 443-468.

Rouwenhorst, K.G., 1999. Local return factors and turnover in emerging stock markets. Journal of Finance $54,1439-1464$.

Sercu, P., 1980. A generalization of the international asset pricing model. Revue de l'Association Française de Finance 1, 91-135.

Sercu, P., Uppal, R., 1995. International Financial Markets and the Firm. South-Western College Publishing, Cincinnati, $\mathrm{OH}$.

Solnik, B., 1974. An equilibrium model of the international capital market. Journal of Economic Theory $8,500-524$.

Solnik, B., 1983. International arbitrage pricing theory. Journal of Finance 38, 449-457.

Stulz, R.M., 1981. A model of international asset pricing. Journal of Financial Economics 9, 383-406.

Stulz, R.M., 1995a. International portfolio choice and asset pricing: an integrative survey. In: Jarrow, R.A., Maksimovic, V., Ziemba, W.T. (Eds.), Finance. Handbooks in Operations Research and Management Science, 9. North-Holland, Amsterdam, pp. 201-223.

Stulz, R.M., 1995b. The cost of capital in internationally integrated markets: the case of Nestlé. European Financial Management 1, 11-22.

Stulz, R.M., 1998. The globalization of equity markets and the cost of capital. Working paper, Ohio State University. 